\title{
La recepción del mito de Medea en la marginación de una mujer: "Patrón" de Abelardo Castillo
}

\author{
The reception of the myth of Medea in the marginalization of a woman: "Patrón" by Abelardo Castillo \\ María Silvina Delbueno \\ Universidad Nacional de La Plata-Universidad Nacional \\ del Centro de la provincia de Buenos Aires, Argentina \\ silvinadelbueno@yahoo.com.ar
}

\section{ReSUMEN:}

En este estudio nos proponemos indagar la recepción del personaje mítico de Medea en el cuento "Patrón" de Abelardo Castillo. La elección radica en los puntos de encuentro de ambos personajes femeninos. Por un lado, hallamos en Paula a una mujer marginal que sufre las expresiones de violencia extrema del maltrato al que la somete su marido, Antenor. Por otro lado, dicha violencia subyace en el mismo territorio de la pampa argentina. Sin embargo, la mujer padece la aporía en una frontera invisible entre su lugar de origen y el alambre que trazó las manos del patrón. Violencia y desterritorialización constituyen los ejes sobre los que se estructura esta pieza en que el personaje femenino revive el sesgo vengativo contestatario del personaje del hipotexto euripideo.

Palabras Clave: Medea, Eurípides, Recepción, Castillo, Violencia, Territorio.

\section{Abstract:}

In this study we resolve to look into the reception of the mythical character Medea in the story "Patrón" by Abelardo Castillo. The decision resides in the points of agreement of both female characters. On the one hand, we find in Paula, a marginal woman that suffers the expressions of extreme violence of the maltreatment she is subjected to by her husband, Antenor. On the other hand, that violence underlies in the same territory of the Argentine pampa. Nevertheless, the woman endures the aporia in an invisible border between her place of origin and the fence that the hands of the "patrón" outlined. Violence and deterritorialization constitute the central points this piece is structured on, in which the female character revives the vengeful controversial bias of the character of the Euripidean hypotext.

KEYWORDS: Medea, Eurípides, Reception, Castillo, Violence, Territory.

\section{INTRODUCCIÓN}

Los mitos griegos ya se consideraban, en su origen, como la reescritura de una historia, lejana y heroica, pero en líneas generales, verídica (De Romilly, 2011, p. 23). Esas reescrituras han llegado hasta nuestros días y, en este sentido, Lorna Hardwick afirma: "The implications for the study of classical texts are important since they suggest that the meaning attributed to an ancient text is shaped by the historical impact of its subsequent reception" (2003, p. 8). El estudio de la recepción clásica no sólo analiza y compara los aspectos lingüísticos, teatrales y contextuales del pasado grecolatino, sino que apunta a conocer mejor la cultura en la que se inscribe la obra actual.

Optamos por el término recepción y no tradición tal como lo constata Maarten De Pourcq:

The term 'reception' has been an important shorthand for the resistance within literary studies against uncritical notions of tradition and the classical. [...] That is why the label 'classical receptions' was coined at the end of the 1990s in order to replace the older concept of 'the classical tradition ' [...] Tradition, as Highet also pointed out, refers to the Latin 'tradere' which means 'handing down to posterity'. The word 'reception ', on the other hand, refers to the act of receiving. The focus is no longer on the lasting influence of the ancient source but on the different meanings, functions and forces an ancient element acquires at the moments of reception (2012, pp. 220-221).

Según nuestro parecer el concepto de recepción involucra al de tradición dado que tanto uno como el otro transportan aquello de lo que hablan a nuestro presente. Pero lejos de traer el pasado griego a modo

Recepción: 09 Octubre 2020 | Aceptación: 06 Noviembre 2020 | Publicación: 01 Diciembre 2020 
de un legado pasivo, inerme, indiscutible, la recepción permite transformarlo, transplantarlo, reescribirlo, reinventarlo de acuerdo con la mirada de cada lector y con la realidad contextual que le toca vivir.

El personaje mítico que nos ocupa en la tragedia de Eurípides da cuenta de una mujer herida, que pierde su territorio, es decir, el lugar de Cólquide que ha habitado en el pasado y el que habita en el presente de la acción dramática, Corinto, y por ello, hiere con una crueldad tan inhumana como indescriptible en un contexto al cual no se puede ajustar. El exilio le significará a esta mujer una manifestación de la violencia por causa de la traición del hombre que la abandona y la despoja de todo. Esta situación engendra en ella el furor vengativo del crimen filicida.

Durante el transcurso del siglo XIX, Medea ha llegado a cobrar una dimensión particular pues aparece como víctima de condiciones socioculturales y políticas entendidas de un modo muy opuesto a la tradición antigua, que la mostraba principalmente como un ente teratológico, maléfico, vengativo y justiciero. Por consecuencia, los siglos XX y XXI encuentran en ella a una mujer despojada que está perdiendo todo: familia, esposo e hijos, y entienden que el filicidio no está provocado solamente por el deseo pasional de venganza tal como lo enfatiza la tragedia griega, sino también por otros móviles, como la liberación que, a través de la muerte, opera la madre a fin de evitar que sus hijos padezcan el igual destino de desposeídos.

La reescritura y reinterpretación constante del mito da cuenta de la polisemia de sentido. ${ }^{1}$ Cada época en nuestro país interpreta de manera diferente este mismo mito, ya que presente y pasado están implicados, porque la cultura griega sigue teniendo vigencia en la cultura argentina. Tal es el caso del cuento de Castillo cuya temática gira en torno a la violencia en el autoritarismo ejercido por un patrón de estancia y la conducta contestataria de una mujer por entero marginalizada. Podemos inferir que la trama se proyecta desde el pasado de la época de Rosas en que la estancia cobraría la metáfora de la Nación hacia el presente de la publicación de esta pieza. Tengamos en cuenta que el cuento se inscribe en una época de violencia político-social que le tocó vivir a la Argentina desde fines de la década de 1950 y, fundamentalmente, a partir de 1970. Así lo expresa el autor en el "Postfacio" a la reedición de este texto:

Cuentos crueles en el que se halla el cuento “Patrón”, fue escrito entre 1962 y 1966, vale decir, en la sonora década del '60, años que no fueron el tiempo dorado e irresponsable que algunos imaginan, sino el preludio de otros años atroces y violentos que siguieron y en los que aún [1981] vivimos. (2018, p. 204).

\section{AlgunAS DEFINICIONES: VIOLENCIA Y TERRITORIO}

Violencia y territorio conforman los dos términos que atraviesan la obra dividida en seis partes en las que el autor combina la narración en tercera persona y el diálogo entre sus personajes. En el territorio de la pampa argentina hallamos la expresión de la violencia que ejerce el hombre sobre su joven esposa.

Si nos detenemos en el sema "violencia", éste aparece como un desborde, una fuerza extrema, excesiva, inseparable de lo humano, en la que el furor, el padecimiento, la desesperación, la locura, se hallan involucrados. Liddell-Scott ya ha dado cuenta del término üßpıs como sinónimo de violencia (1996, p. 1842). A su vez Robert Wolff lo describe como: "Strictly speaking, violence is the illegitimate or unauthorized use of force to effect decisions against the will or desire of others" (1969, p. 606). Por otra parte, Fernando Miguel Pérez Herranz analiza dicho término desde la antigüedad:

Violencia es un término vinculado al vis latino, que suele verterse por 'fuerza, vigor, potencia, empleo de la fuerza física, cantidad, abundancia de una cosa'. Es fuerza natural, fuerza bruta o fuerza vital que el propio cuerpo despliega. La violencia es fuerza en acción, la fuerza cuando se ejerce, y, por contraposición, no hay violencia si la fuerza no se manifiesta en una acción. Violencia significa 'carácter feroz, salvaje, bravío'. En griego el término correspondiente es ís = músculo, fuerza, vigor y se remite a $\beta i \alpha$, fuerza vital, la fuerza del cuerpo $(2013$, p. 39$)$.

En castellano aparece en el siglo XIII, vinculada a la imposición por la fuerza física del varón. La noción de "violencia" significa "forzamiento" o "intimidación". Si bien originariamente se vincula con la fuerza 
física, se ha distinguido la violencia simbólica donde el poder simbólico literalmente "construye un mundo imponiendo orden a la realidad" (Femenías, 2013, p. 19).

En el espacio trágico, la violencia según Crespi está ligada a las “técnicas de agresión” que se disponen a través de tres tipos de "armas": la anulación o frustración por la mirada (mirar al otro es desorganizarlo, inmovilizarlo en su desorden, es decir, "mantenerlo en el ser mismo de la nulidad"), la amenaza de muerte o el chantaje y "el arte de la agresión verbal” (2014, p. 23).

En "Patrón" la violencia es ejercida dentro de un mismo territorio. Por ello, tendremos en cuenta el concepto de territorio (territorium) que entendemos es un término que se acerca a región, que se relaciona con la construcción del espacio, y que involucra indisolublemente la noción de borde o de límites. Y si hacemos alusión a límites, entonces es necesario remitirnos al concepto de frontera. En esta línea Newman enfatiza: "The frontier is an indefinite area on both sides of the boundary line" (2003, p. 142). Este concepto móvil propone una demarcación, una línea divisoria socio-cultural, geográfica, etnográfica, económica, política, religiosa, simbólica, etc. ${ }^{2}$

Ahora bien, en relación con los términos anteriores, nos remitimos al concepto de lugar que Biglieri define:

este se identifica con la habitación humana del espacio, ya sea transitoria o permanente: un lugar es un espacio "humanizado". Esto significa que vivir (en) un espacio (Lefrebvre) y sentirlo (Tuan) es una manera de estar en el mundo, de instalarse las sociedades en él y, por lo tanto, de conferirle una dimensión histórico-temporal. En síntesis, un lugar es un espacio en el cual se desarrollan procesos sociales; dicho de otra manera, no es el "escenario" estático de los hechos que en él "tienen lugar", sino también un proceso que se despliega en una duración temporal. (2018, pp. 2-3).

$\mathrm{Al}$ mismo tiempo tendremos en cuenta la visión de Cammarata cuando define territorio como: "El portador de una identidad colectiva expresada en valores y normas que interiorizan sus miembros [...]" (2006, p. 357).

Por lo expuesto, la universalidad del mito, en especial, del mito griego, se halla plasmada en este cuento y su reelaboración subsumida, en la particularidad de la pampa, que pesará como una fatalidad sobre los personajes. La literatura moderna en su anhelo de refundir un texto en un contexto nuevo, en su ansia por dotar de nuevos sentidos a las antiguas tramas míticas, prolonga esa vieja tradición de relectura y reinterpretación (García Gual, 1999, p. 185).

\section{DELIMITACIÓN DE LOS ESPACIOS}

Si nos atenemos al hipotexto griego, Eurípides especifica la ubicación de la obra inmediatamente. En este sentido, Lloyd afirma:

The scenic space in Euripides is always located in front of a building represented by the skene. This space is never treated as private, as a room inside the house might have been. Euripides sometimes brings characters onto the stage when they might more naturally have remained indoors, but the result is that they are now in a position to interact with strangers.[...] The scenic space in Euripides is an intermediate zone between the privacy of the interior of the skene and the world of public affairs. He often has a nearby offstage place at which decisions are made in perhaps unpredictable ways about the characters onstage, and this displacement of political power from the scene of the action is a distinctive feature of his plays. [...] Both Medea and Heracles are set in front of private houses in cities, and the dramatic importance of the offstage royal palace is particularly notable in Medea [...] (1992, pp. 345).

Ahora bien, la pieza de Castillo, ubicada en la generalidad del macro-espacio geográfico de la pampa argentina, se inserta en la particularidad del campo, micro-espacio delimitado por el cerro Patrón y por la estancia, La Cabriada, posesión del protagonista, Antenor Domínguez. ${ }^{3}$

Si consideramos el espacio como entorno natural inferimos que todos los personajes de este cuento habitan el territorio de la pampa, lugar que hace alusión a la región geográfica, histórica, social y económica. Dichos 
personajes deambulan en lugares específicos como son el pueblo, el campo y la propiedad rural entre los que se demarca una línea invisible, una frontera infranqueable.

Ahora bien, lejos de la maquinaria demiúrgica euripidea, hallamos en esta obra a una despojada, entre un lado y el otro lado del alambre trazado por las manos del patrón. ${ }^{4}$ Esta polaridad operará desde el campo cultural como delimitación de antagonismos y pertenencias hasta nuestros días. ${ }^{5}$

\section{Planos múltiples}

La manifestación de la violencia en esta pieza aparece claramente trazada a partir del plano genérico: la violencia masculina por sobre la femenina. La crueldad sin límites de un hombre mayor y el sometimiento de su joven esposa derraman en otros planos relacionados por entero con éste. Quizá por ello, el título de Castillo recae sobre la delimitación de la función del hombre como patrón, estanciero, y no sobre el personaje femenino claramente obliterado. ${ }^{6}$ La violencia en este cuento entrecruza el eje temporal que opera a modo de segundo plano, pues el presente se halla imbricado en el pasado inmediato de manera permanente. La irradiación de la violencia masculina del protagonista parecería afianzarse por la posesión del territorio, a modo de tercer plano, consolidado por varias hectáreas de campo adquiridas de manera sombría. ${ }^{7}$ Directamente relacionado con éste, podemos hallar el cuarto plano, el socio-económico y político, es decir, el poderío de un hombre, un estanciero frente a la precariedad en la que ha vivido Paula, su mujer. Finalmente, el quinto plano, como todos los anteriores, aparece signado por la violencia, en este caso la violencia femenina que involucra la transformación de una mujer aporética. En el momento del desenlace del cuento opera la conexión con la trama de Eurípides, el de una mujer vengativa y presumiblemente filicida.

\section{LA VIOLENCIA DE LA COSIFICACIÓN FEMENINA}

La expresión de la violencia atraviesa toda la pieza y se enfatiza en la dominación-posesión del hombre sobre una joven mujer. Sin embargo, no debemos olvidar que esta posesión deviene de un acto de violencia menor, enmascarado, dentro del mismo ámbito femenino. Se trata de la "entrega" de la abuela a su nieta Paula al mejor postor cuando expresa: “-Mire que no es obligación.- Ahora que usté sabe cómo ha sido siempre don Anteno con una, lo bien que se portó de que nos falta su padre. Eso no quita que se haga su voluntad" (Cast. "Pat", p. 133). ${ }^{8}$

En esta cita podemos evidenciar varios aspectos que dan cuenta del imperativo del patrón por sobre el resto de los personajes. ${ }^{9}$

En primer término, desde el punto de vista socio-lingüístico, el nombre Antenor pierde la última consonante cuando es pronunciado por los trabajadores del campo, por la partera y por la abuela, como un síntoma de ruralidad y de diferenciación social de clases.

En segundo término, desde el punto de vista genérico, la entrega de esta joven adolescente, de dieciséis o diecisiete años, opera a modo de intercambio que, en alguna medida nos retrotrae al mítico vellocino del hipotexto euripideo cuando el narrador sostiene: "[...] -la abuela no sabía muy bien; tampoco sabía muy bien cómo hacer para disimular el asombro, la alegría, las ganas de regalar, de vender a la nieta [...]" (Cast. "Pat", p. 134.). Es decir, así como Jasón toma posesión del preciado objeto y con él a la bárbara Medea, de manera similar Antenor, dueño absoluto de la posesión de la tierra, tomará a Paula. Queda claramente excluida en el cuento la secuencia del robo del vellocino como forma de recuperación del trono perdido por parte del argonauta. A partir de la joven Paula, la abuela cancela, a modo de agradecimiento-trueque, la deuda adquirida para con el patrón ya que éste había sostenido a ambas desde la desaparición del padre, un puestero de la estancia muerto en el incendio del 30. Esta fecha constituye el único dato temporal presente en la obra. 
En tercer término, desde el punto de vista socio-económico, la hija de un puestero pasará a ser la esposa del hombre más adinerado del partido. Entonces la mejor o única opción para una joven carente de todo se conforma en la posibilidad de un matrimonio conveniente.

\section{LA VIOLENCIA DEL IMPERATIVO MASCULINO}

La concertación del matrimonio porta por un lado, desde el ámbito femenino la cancelación de una deuda pero además, por otro lado, porta desde el ámbito masculino la necesidad de descendencia. Así Antenor afirma ante la abuela: "-Quiero casarme con su nieta-[...] Se me ha dado por tener un hijo, sabes. [...]-Mucho para que se lo quede el gobierno, y muy mío" (Cast. "Pat", p. 133.). El imperativo formulado por el hombre a partir del verbo volitivo, a modo de orden que entroniza el deseo del que manda, adquiere su correlato en otro imperativo, el de la posesión con el fin último de la descendencia. De esta manera, esta nueva posesión parecería ser extensiva de la posesión anterior de la tierra.

La primera comunicación del hombre frente a Paula se reduce a una expresión despojada de cualquier declaración amorosa: "vaya, que la vieja quiere hablarla" (Cast. "Pat", p. 134) con la que deja en claro que la joven deberá aceptar la voz femenina ancestral que a su vez acepta la demanda masculina de Antenor.

Cuarenta y tantos años resulta la diferencia de edad que media entre ambos y, quizá por ello, Antenor necesita demostrar durante la celebración su valía frente a las miradas inquisidoras del otro social, la peonada: "Duro, retorcido como un alambre, bailando esa noche, demostrando que de viejo sólo tenía la edad, zapateando un malambo hasta que el peón dijo está bueno, patrón, y él se rió, sudado, brillándole la piel curtida. Oliendo a padrillo" (Cast. "Pat", p. 134). ${ }^{10}$ Este desafío en el alarde, en la mostración masculina, resulta comparativo con un hecho del pasado cuando el hombre tomó posesión de la tierra: "[...] Porque el trato era "hasta que amanezca", y él estaba acostumbrado a estas cláusulas viriles, arbitrarias (Cast. "Pat", p. 135). ${ }^{11}$

Una vez instalados en el territorio que pertenece al patrón, éste renueva el imperativo de la descendencia que se condice con la virilidad antes demostrada durante el festejo: "Todo lo que quiero es mujer en la casa, y un hijo, un macho en el campo- [...] - Todo va a ser para él, entendés. Y también para vos. Pero andá sabiendo que acá se hace lo que yo digo, que por algo me he ganao el derecho a disponer.-[...]"(Cast. "Pat", p. 135).

Con este segundo imperativo, pues el primero estuvo referido al matrimonio, el patrón delimita claramente los espacios y la sexualización de los mismos: el adentro, la casa, como pertenencia del ámbito femenino, y el afuera, el campo, como pertenencia del ámbito masculino, ${ }^{12}$ tal como sucede en la concepción de la tragedia griega.

Asimismo detona el mecanismo de violencia imperativa de un hombre que ordena y una mujer que debe obedecer. Por ello, la herencia de esa tierra será destinada, en primer lugar, al primogénito y, en segundo lugar, a la esposa. Esta llega a conformar la cosificación de un instrumento destinado a la procreación y la herencia y, por ello, el enlace entre el apartado primero y el segundo se conforma con el autoritarismo del hombre: "Vení a la cama" y la consecuente toma de posesión de la mujer: "No la consultó. La tomó, del mismo modo que se corta una fruta del árbol crecido en el patio. [...] La cortó” (Cast. "Pat”, p. 135).

\section{LA VIOLENCIA EN UNA MUJER SIN TERRITORIO}

La protagonista euripidea se constituyó en una transterrada, en una mujer que abandonó su tierra de Cólquide y no pudo ajustarse a la tierra griega de Corinto, tierra del argonauta. Muy contrariamente, en el caso de Paula, su tierra de origen y pertenencia la conforma el territorio de la pampa argentina ya que, al parecer, ha nacido en él. Sin embargo, en el momento de concertar el matrimonio con Antenor, pierde su lugar de pertenencia en el puesto que compartía junto con su abuela, una nodriza al modo griego, y pasará 
a formar parte del territorio de la vieja casona que domina el patrón: "[...] estaba acostumbrado a entender suyo todo lo que había de este lado de los postes y del alambre [...]" (Cast. "Pat", p. 135). ${ }^{13}$ Por ello, hallamos en Paula a una mujer despojada, sin territorio, a pesar de que habita la misma tierra que el hombre. Este constituiría el primer punto de encuentro con la protagonista del hipotexto euripideo.

El territorio podría definirse en su temporalidad, se construye, amplía o reduce con las acciones de los hombres. Por ello Antenor demarca su propiedad de este lado del alambrado. Nuevamente la violencia masculina se imprime sobre la femenina porque al igual que el patrón tomó posesión de la tierra que se abarca en una noche de a caballo "[...] clavó la estaca y empezó a ser don Antenor" (Cast. "Pat", p. 135), toma posesión de la mujer, como prolongación y sinonimia de la fertilidad de la tierra. La diferencia estriba en que la posesión de Paula se aviene con la legitimación de un matrimonio, en tanto que la posesión de la tierra resulta turbia y no legitimada: "[...] los más suspicaces, aseguraban que el hombre caído junto al mostrador del Rozas tenía algo que ver con ese trato [...]" (Cast. "Pat", p. 135).

Ahora bien, el espacio que habita Paula ha sido cercado por la tranquera y el alambrado que tensó la mano de Antenor, y si bien estos elementos campestres permitirían comunicar los espacios, el afuera del campo y el adentro de la estancia, ello no es posible pues la mujer comienza a afianzar una situación de aporía, sin salida por su condición matrimonial.

Entonces la joven deviene una cosificación que forma parte del territorio conquistado por este hombre. El afuera no sólo significa el lugar de acceso y de comunicación, sino también y en este caso en particular, el lugar del peligro, del acecho, ámbito de pertenencia masculina en la disputa de dos hombres por la mujer.

Ella cruzaba los potreros, buscándolo, y un peón asomó detrás de una parva; Paula había sentido la mirada caliente recorriéndole la curva de la espalda, como en los bailes, antes. Entonces oyó un crujido, un golpe seco, y se dio vuelta. Antenor estaba ahí, con el talero en la mano, y el peón abría la boca como en una arcada, abajo, junto a los pies del viejo. (Cast. "Pat", p. 136).

El comportamiento conductual de Antenor resulta de una crueldad extrema y podríamos escindirlo en tres instancias. En un primer momento, desde la ejecución de la acción sale a la defensa de su pertenencia ante el peligro que significa la presencia de otro hombre, presumiblemente joven, y para ello utiliza el instrumento de castigo: el talero.

En un segundo momento, desde la palabra fustiga a la esposa por no permanecer en la estancia, en el oíkos. La explicación de ésta que radica en el malestar de su abuela, trae aparejada involuntariamente un acto de protección de la esposa hacia Antenor, custodiado y amenazado por la presencia silente de los otros hombres, los peones. La contienda criolla, que adolece de ciertos tintes de heroicidad masculina, sobreviene a causa de la belleza (rasgo que la acercaría a la protagonista euripidea) y de la juventud de la mujer (rasgo opuesto respecto de su par griego) que, a su vez, operaría a modo de parámetro comparativo en el aspecto poco favorable del patrón: “[...] la muchacha era una mujer grande, ancha y poderosa como un animal, una bella bestia y chúcara a la que se le adivinaba la violencia debajo de la piel. El viejo, en cambio, flaco, áspero como una rama" (Cast. "Pat", p. 136).

En un tercer momento, la conducta feral del patrón prima en la expresión vertida al peón, al presunto agresor, a través de la visión cosificada de su mujer: “[...] -Si andás alzado en cuanto me dé un hijo te la regalo" (Cast. "Pat", p. 137). ${ }^{14}$

Entonces, la protección que para la mujer significaría el resguardo del oî́kos y por extensión el resguardo que brinda el amparo de un hombre, se halla inmediatamente anulada por la violencia conductual de Antenor para con Paula y el claro deber que para él esta tiene que cumplir.

Si tenemos en cuenta a la protagonista euripidea, podemos observar que a diferencia de ella y a la retórica contestataria empleada, la mujer de Castillo guarda silencio ante las sucesivas agresiones masculinas. Sin embargo, ese silencio resulta enconado y anticipa la violencia de la trama por venir. 


\section{LAS EXPRESIONES DE LA VIOLENCIA MASCULINA}

El paso del tiempo en un matrimonio despiadado y cifrado en la extensión de dos años desde la llegada de Paula a la casa grande enloquecen al patrón que se siente estafado por la ausencia del hijo y, como consecuencia, en un primer término, lo exterioriza desde el rencor de su mirada y el olor a caa frecuente. En un segundo término, la conducta violenta del agresor se exterioriza en el maltrato verbal y posteriormente, en la agresión física hacia la mujer.

[...] Al final del tercer año, quedó encinta. Debió de haber sido durante una de esas noches furibundas en que el viejo, brutalmente, la tumbaba sobre la cama, como un animal maneado, poseyéndola con rencor, con desesperación. Ella supo que estaba encinta y tuvo miedo. De pronto sintió ganas de llorar; no sabía por qué, si porque el viejo se había salido con la suya o por la mano brutal, pesada, que se abría ahora: ancha mano de castrar y marcar, estallándole, por fin en la cara (Cast. "Pat", p. 137). [...] El bofetón la sentó en la cama; pero no lloró. Se quedó ahí, odiando al hombre con los ojos muy abiertos. La cara le ardía (Cast. "Pat", p. 137).

La violencia masculina opera en un in crescendo que va desde el maltrato verbal hasta la agresión física. Paula no tiene adónde ir, carece de la protección que pudiera brindarle su abuela, ya muerta, se encuentra sola, aporética y librada al despotismo de un hombre. El cumplimiento de su deber matrimonial a partir del embarazo, lejos de brindarle consuelo, la sume en el temor del porvenir. Frente a ello, la mujer experimenta frente a Antenor una gradación que oscila del sometimiento al odio. Recordemos que el anuncio de este embarazo, única razón por la que Paula puede alejarse de la estancia para llegar al poblado y una vez en él, a la casa de la partera, constituye la secuencia inicial de este cuento.

\section{LA ANIMALIZACIÓN DE LA MUJER Y LA ANIMALIZACIÓN DEL HOMBRE}

La sumisión violenta de la mujer por el hombre, el encierro al que está sometida dentro de la estancia y los fines exclusivamente reproductivos de un matrimonio concertado son los elementos que signan a Paula como una mujer aporética. El imperativo del hombre de alguna manera podría relacionarse con el plano socio-político de la República Argentina, luego de la Conquista del desierto en que los estancieros manejaban despóticamente los asuntos del campo como los asuntos del Estado. ${ }^{15}$

Sin lugar a dónde ir ni escapatoria posible, la mujer gradualmente experimenta en el encierro un proceso de animalización creciente. Dicha animalización se sostiene de manera rotunda al verse reflejada en una ternera: "Una ternera boca arriba [...] Paula se reconoció en los ojos de la ternera" (Cast. "Pat", p. 138), maniatada y quemada por el trabajo rural de la yerra. Desde la descripción de la belleza chúcara de la joven, "una mujer ancha y poderosa como un animal", el autor enfatiza la asimilación comparativa con el animal sometido por la fuerza del hombre y sin escapatoria: "nadie como el viejo para voltear un animal y descornarlo o caparlo de un tajo" (Cast. "Pat", p. 138). ${ }^{16}$

Dicha animalización femenina podría extenderse al hombre en el momento en que es embestido por un toro y Paula intenta fallidamente comunicarle su embarazo. ${ }^{17}$ La valía de Antenor queda denigrada desde tres perspectivas. En primer término, desde la mirada del otro social en la que aparecen los peones. En segundo término, desde la hombría anulada de aquí en delante para el mandato y la realización de los trabajos rurales. En tercer término, desde la violencia del autoritarismo ejercido sobre Paula: "Había quedado sobre el alambrado de púas, como un trapo puesto a secar" (Cast. "Pat", p. 139). Encontramos que este episodio tiene su antecedente en la página 137 del relato, apenas esbozado por el autor. Un hombre acostumbrado a ordenar y a ser obedecido pierde la movilidad y pierde la capacidad del habla. Su poder anterior se transforma en postración. A partir de ahora pasará a ser un testigo silenciado de los hechos que rodean su vida. ${ }^{18} \mathrm{La}$ violencia de la soledad y de la aporía a la que el hombre confinó a Paula, a partir del accidente converge cíclicamente sobre este patrón y por ello podemos concertar la relación de traspaso de victimario a víctima de 
los sucesos impuestos por el destino. El resto de los personajes: el médico, el capataz de La Cabriada, el viejo Fabio y la mujer que ayudaba a Paula en la cocina constituyen los únicos que rodeaban el mundo reducido y devastado de Antenor.

\section{LA VIOLENCIA CONTESTATARIA DE UNA MUJER}

No es casual que la puerta de la habitación en la que reside Antenor permanezca cerrada con llave por la misma esposa: "[...] (una llave grande, que Paula llevará siempre consigo, colgada a la cintura) [...]" (Cast. "Pat", p. 140). A la degradada postración a la que está sujeto Antenor, Paula incrementa otra degradación: el encierro al que lo somete. En el presente del relato, la mujer deviene en única responsable de la estancia y en cierta medida, comienza a transformarse conductualmente en lo que ha sido el Patrón, la autoridad que decide el destino del otro social en general y el destino de su esposo, en particular. A partir de este momento de la acción, los roles se han invertido. Ese cambio de situación la metamorfosea en un ser vengativo, implacable, rasgo este último que la asimila a la mujer del hipotexto euripideo. Contestataria a las afrentas recibidas por el hombre en el tiempo pasado, Paula en el presente de la acción logra encarnar la violencia al ser temida por el hombre que anteriormente la abatió. En la voz narradora:

[...] El silencio se le pobló entonces con una presencia extraña y amenazadora, que acaso se parecía un poco a la locura, sí, alguna noche, cuando ella venía con una lámpara, el viejo miró bien su cara: eso como un gesto estático, interminable, que parecía haberse ido fraguando en su cara o quizá sólo en su boca, como si la costumbre de andar callada, apretando los dientes, mordiendo algún quejido que le subía en puntadas desde la cintura, le hubiera petrificado la piel. O ni necesitó mirarla. Cuando oyó girar la llave y vio proyectarse larga la sombra de Paula sobre el piso, antes de que ella dijera lo que siempre decía, el viejo intuyó algo tremendo. Súbitamente, una sensación que nunca había experimentado antes. De pronto le perforó el cerebro, como una gota de ácido: el miedo. [...] Ella dijo:-Va a tener el chico (Cast. "Pat", p. 141).

Entonces el paradigma conductual violento hombre-mujer se ha invertido. La mujer se ha masculinizado para librar la batalla silente frente a un hombre debilitado, minusválido, feminizado en el dolor. ${ }^{19}$

Las únicas palabras que entablan la comunicación entre ambos esposos son las que refiere Paula próxima al parto. La mujer ha decidido parir sola en el dolor y en ello hallamos cierta alusión a los versos de la heroína euripidea, vv. 250-251. Desde la postración, el hombre sólo puede ver "el campo y el vientre hinchado de su mujer”, las dos únicas posesiones sobre las que ya prácticamente no tiene incidencia ni sobre las que puede ejercer su autoritarismo. ${ }^{20}$ Recordemos que el niño es, en el derecho patriarcal antiguo, propiedad del padre y representa para él la continuación de la estirpe y de este modo ha acontecido en este cuento. Por ello, la madre no tiene seria necesidad cultural respecto de ellos (Foley, 1994, p. 243).

Desde la debilidad masculina que lo mantiene inerte y sin habla, la mujer comienza a fraguar contestataria la trama de la maquinación vengativa, la más extrema de las expresiones de violencia.

\section{LA TRAMA SECRETA EN LA VIOLENCIA DEL ABANDONO}

La crueldad sin límites del hombre adquiere la expresión contestataria de la mujer que abandona. El primer eslabón en el engranaje de la venganza anclada en el abandono tiene lugar cuando Paula decide deshacerse del personal que la acompaña. Desembarazarse de las personas que la ayudaban podría adquirir el correlato en espejo invertido respecto de la heroína euripidea al deshacerse de sus enemigos: Creusa y Creón. Criada en las tareas rurales y en la ausencia de conocimientos culturales, sin embargo, Paula es capaz de pergeñar el plan de venganza. En ello igualmente se acerca a la protagonista euripidea pues como ella vengará cada una de las violencias verbales y corporales cometidas por el hombre y cíclicamente le devolverá el favor. "Nació en invierno; era varón. Paula lo tuvo ahí mismo" [...] (Cast. "Pat", p. 141). Sin embargo, la loca alegría que le produce a Antenor este llanto en la noche resultará efímera. Cabe destacar que a lo largo de todo el cuento, la protagonista alude a su hijo como "el chico" y no con la utilización de posesivos como 
mi hijo o nuestro hijo, pues no lo reconoce como propio sino como objeto cosificado, producto de las reiteradas violaciones.

Ahora bien, la mostración del recién nacido al padre, lejos de la esperada celebración, también significa un acto de violencia, el último del que es capaz Antenor frente a su mujer:

[...] Como si hubiera estado esperando aquello, el viejo soltó las correas y tendió el brazo libre hacia la mujer; con el otro se apoyó en la cama, por no aplastar al chico. Sus dedos alcanzaron a rozar la pollera de Paula, pero ella, como si también hubiese estado esperando el ademán, se echó hacia atrás con violencia. Retrocedió unos pasos; arrinconada en el ángulo del cuarto, al principio lo miró con miedo. Después, no [...]. (Cast. “Pat", p. 142).

La mujer ya ha decidido la venganza en el abandono de ambos, padre e hijo. ${ }^{21}$ Este castigo será cumplido cuando Antenor vea morir en sus manos al recién nacido, único propósito de su matrimonio. La mujer no se ha manchado las manos con la sangre del niño, tal como sucede con la protagonista euripidea. El sulki opera como instrumento de escapatoria, símil de carro alado clásico con la impronta de la pampa argentina. El hecho de arrojar la llave de la puerta al aljibe anula cualquier posibilidad de rescate con vida, en especial del recién nacido. ${ }^{22}$ Paula presumiblemente habrá consumado el filicidio en primer lugar, y el asesinato por abandono de persona de su esposo, en segundo lugar.

Como una mujer itinerante escapará buscando otro destino en la pampa, al igual que la protagonista euripidea lo hará en Atenas.

\section{ConcLusión}

Desde los estudios de recepción este cuento mantiene puntos de encuentro respecto del hipotexto euripideo. En primer término, hallamos a una mujer que, al igual que la Medea euripidea, ha perdido su territorio aún dentro del mismo territorio de la pampa argentina. En segundo término hallamos a una mujer vengativa. Y, finalmente, invulnerable logra la huida. Procederemos al análisis detallado de cada uno de estos puntos.

En primer lugar, Paula habita el territorio de la pampa argentina pero sin embargo, desde el momento en que aparece pactado el matrimonio con Don Antenor, deja su pertenencia identitaria social como hija de un puestero ya fallecido para pasar a ser a la esposa del hombre más adinerado del partido. Ese traspaso tiene como correlato la pérdida de su territorio, pues habita la vieja casona, "de este lado del alambre de púas”, que significará la posesión a escala de objeto de todo cuanto pertenece al patrón. Esta situación trae aparejada el silencio casi permanente que sostiene esta mujer frente al mandato imperativo de un hombre extremadamente cruel. Las expresiones de violencia, tanto verbales como físicas, comienzan a hacerse manifiestas desde el momento del encuentro. Paula sólo debe obedecer y cumplir con su deber matrimonial: el nacimiento de un hijo para el patrón. Por ello, la frontera espacial esbozada en la tragedia griega entre Cólquide-Corinto opera en el cuento de Castillo dentro del mismo territorio argentino, en el trazado de un alambrado que divide la pertenencia de un patrón de estancia frente a la hija de un puestero. El antagonismo resulta visceral, pues está propuesto desde el interior del trazado geográfico-político de la pampa y, a pesar de las diferentes identidades de los personajes que pueblan este territorio, todos comparten una misma nacionalidad.

El segundo punto de encuentro con la mujer del hipotexto griego consiste, por un lado, en la belleza extraña, chúcara, de una mujer en la que presuponemos rasgos mestizados, derivados de la unión entre los antiguos pobladores autóctonos y el resabio de los conquistadores españoles. Del mismo modo Medea portaba una belleza bárbara, extraña por su identidad colquidense frente a los griegos.

Por otro lado, la maquinación de su venganza contestataria a causa de los reiterados maltratos recibidos deviene en el hecho de que una vez nacido el hijo de ambos, la mujer encierra y abandona al padre inválido y carente de voz junto a su recién nacido. Si bien la mujer no mata con manos filicidas, sus manos se transforman en instrumento filicida al arrojar la llave de la puerta al aljibe y dejar en soledad extrema a padre e hijo. 
Entonces Paula asume un acto de violencia final como consecuencia de los múltiples actos de violencia a los que estuvo sometida por parte de su marido y patrón.

Finalmente, la heroína euripidea como la mujer de Castillo huyen invulnerables, una a través del firmamento y la otra en la inmensidad de la pampa.

La tragedia griega, el mayor hipotexto sobre el que se asienta la obra estudiada, se cierra con una imagen que simula un campo de batalla. Medea desde las alturas, desde ese más allá, permanece vencedora. De la misma manera, la heroína argentina pertenece, por nacimiento y cultura, a ese "allá" y al "otro lado" de ese "límite", que pasa por ese "medio" invisible pero "ancho" y "grande": la frontera (Biglieri, 2014, p. 6). La mujer ha librado una batalla y ha vencido.

Una lectura en clave política recepciona la violencia que atraviesa la totalidad de la pieza y aparece demarcada en la violencia masculina por sobre la femenina. Entonces destacamos la crueldad sin límites de un hombre mayor y adinerado y el sometimiento de su joven esposa.

Esta obra representa el modo peculiar de recepción del mito de Medea en la literatura argentina. Se trata de un texto narrativo en que aparecen nuestras íntimas contradicciones en la pampa bonaerense. El autor nos brinda la posibilidad de reflexionar sobre los acontecimientos históricos religados al pasado y revisados en el presente actual.

\section{Bibliografía}

Biglieri, A. A. (2014). Curso Internacional: “Tradición y recepción de los clásicos en Latinoamérica”. Organizado por el Centro de Estudios Latinos, del Instituto de Investigaciones en Humanidades y Ciencias Sociales (Facultad de Humanidades y Ciencias de la Educación), Universidad Nacional de La Plata / CONICET. Inédito.

Biglieri, A. A. (2018). El poder del centro: espacios y lugares de la pampa. Armiliar, 2, 1-14.

Boehm, I. (2015). Pur concept, élément naturel ou réalité édifiée de main d'homme? À propos du vocabulaire de la frontière en grec ancien. Cabiers des études anciennes, LII, 19-45. Recuperado de http://etudesanciennes.revu es.org $/ 822$.

Borges, J. L. (1984). Obras completas. Buenos Aires: Emecé.

Cammarata, E. B. (2006). El turismo como práctica social y su papel en la apropiación y consolidación del territorio. En G. de Lemos; M. Arroyo; M. L. Silveira (Ed.), América Latina: cidade, campo e turismo (pp. 351-366). San Pablo: Clacso, Consejo Latinoamericano de Ciencias Sociales.

Castillo, A. (2018). Cuentos completos. Buenos Aires: Alfaguara.

Cortázar, J. (1951). Bestiario. Buenos Aires: Sudamericana/Planeta.

Crespi, M. (2014). Fantasmas de la violencia. Notas sobre un tema de Roland Barthes. En A. M. Zubieta (Comp.), Mapas de la violencia. Filosofía, teoria literaria, arte y literatura (pp.19-43). Bahía Blanca: Universidad Nacional del Sur.

Cureses, D. (1964). La frontera. Buenos Aires: Ediciones El carro de Tespis.

Chevalier, J. y Gheerbrand, A. (1986). Diccionario de simbolos. Barcelona: Herder.

De Pourcq, M. (2012). Classical Reception Studies: Reconceptualizing the Study of the Classical Tradition. The International Journal of the Humanities, 9 (4), 219-226.

De Romilly, J. (2011). La tragedia griega. Madrid: Gredos.

Fantauzzi, S. (2006). La relación entre guerra y política en Hannah Arendt. En R. R. Gatell (Ed.), Sobre la guerra y la violencia en el discurso femenino (1914-1989) (pp. 115-131). Barcelona: Universitat de Barcelona.

Femenías, M. L. (2013). Violencias cotidianas (en las vidas de las mujeres) Los ríos subterráneos. Rosario: Ediciones prohistoria.

Fernández Bravo, A. (1999). Literatura y frontera. Procesos de territorialización en las culturas argentina y chilena del siglo XIX. Buenos Aires: Sudamericana. 
Foley, H. (1994). The concept of women in Athenian Drama. En H. Foley (Ed.), Reflections on Women in Antiquity (pp. 127-168). New York: Gordon and Breache Science Publishers.

García Gual, C. (1999). Sobre la interpretación literaria de mitos griegos: ironía e inversión del sentido. En D. Villanueva, A. Monegal y E. Bou. (Ed.), Sin fronteras: Ensayos de Literatura Comparada en homenaje a Claudio Guillén (pp. 183-194). Madrid: Castalia.

González, J. R. (2000). Jasón de Alemania. Buenos Aires. (Inédita).

Güiraldes, R. (1986). Don Segundo Sombra. Buenos Aires: Editorial Ayacucho.

Hardwick, L. (2003). Reception Studies. Oxford: Oxford University Press.

Heródoto. (2002). Histories. Book IX. Cambridge: University Press.

Larrauri, M. (2006). No se gana la Guerra con la fuerza. En R. R. Gatell (Ed.), Sobre la Guerray la violencia en el discurso femenino (1914-1989) (pp. 103-115). Barcelona: Universitat de Barcelona.

Liddell, H. G. \& Scott, R. (1996). 1968. [1843]). Greek-English Lexicon. Oxford: Clarendon Press.

Lloyd, M. (1992). The Agon in Euripides. Oxford: University Press.

Lojo, M. R. (1994). La "Barbarie" en la narrativa argentina (Siglo XIX). Buenos Aires: Ediciones Corregidor.

Loreaux, N. (2004). Las experiencias de Tiresias (lo masculino y lo femenino en el mundo griego). Barcelona: Acantilado.

Nápoli, J. T. (2007). Eurípides. Tragedias. Introducción, traducción y notas de J. T. Nápoli. Buenos Aires: Colihue Clásica.

Newman, D. (2003). Boundaries. En J. Agnew, K. Mitchell y G. Toal (Geraóid O Tuathail) (Ed.), A Companion to Political Geography (pp. 123-137). Malden, MA and Oxford: Blackwell.

Pérez Herranz, F. M. (2013). El (inmarcesible) árbol del bien y del mal: entre el atractor maligno y el prójimo. En F. M. Pérez Herranz (Ed.), La cólera de Occidente. Perspectivas filosóficas sobre la guerra y la paz (pp. 23-60). Madrid: Plaza Valdés Editor.

Pugliese, M. R. (2011). Derecho, Estado y religión. La historia del matrimonio civil en la Argentina. Buenos Aires: Editorial Biblos.

Sarlo, B. (2007). Borges, un escritor en las orillas. Buenos Aires: Seix Barral.

Sbarra, N. H. (2008). Historia del alambrado en la Argentina. Buenos Aires: Letemendia Casa Editora.

Shaw, M. (1975). The female intruder. Women in fifth-century drama. CPH 70 (4), 255-266.

Wolf, C. (1996). Medea. Voces. Madrid: Debate.

Wolff, R. P. (1969). On Violence. Journal of Philosophy, 66 (19), 601-606.

Zayas de Lima, P. (2010). Mitos griegos en el discurso teatral argentino. Telón de fondo, Revista de teoría y crítica teatral, 11, 1-21. Recuperado de http://www.telondefondo.org. (12/04/2015)

Zeitlin, F. (1992). Playing the Other: Theater, Theatricality, and the Feminine in Greek Drama. En J. J. Winkler y F. Zeitlin (Ed.), Nothing to do with Dionisos? Athenian Drama in its Social Context (pp. 63-96). Princeton: University Press.

\section{Notas}

1 Zayas de Lima (2010, p. 68) afirma: "La incorporación del mito al hecho escénico permite reconocer y decodificar ciertos símbolos clave que dan sentido de una identidad compartida a nuestra sociedad, al tiempo que proporciona al teatro una coherencia secreta que pervive a lo largo de épocas distantes en tiempo y en espacio, y permite que unos relatos se conviertan en metáforas de otros."

2 Boehm (2015, pp. 19-45) afirma: "Le terme öpos est tout à fait à part au sein de ce champ sémantique de la «frontière».

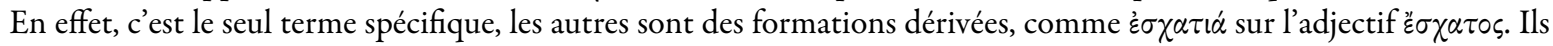
sont liés, comme nous le savons, à la notion d'《extrémité», de confins, c'est-à-dire de ce qui est à longue distance d'un élément de référence. Je commencerai donc par réunir quelques remarques sur le terme öpos avant de m'intéresser à ceux qui, nous le verrons, en sont plus éloignés, tant sur le plan morphologique que sur le plan sémantique." 
3 El nombre Antenor nos llama la atención porque lo lleva el personaje que aparece en Homero, Ilíada III.203-224 "el sensato Antenor", quien realiza acotaciones y pareceres sobre la figura de Ulises en el diálogo que mantienen Helena y el rey Príamo. También hallamos a Antenor Barragán en la obra argentina de Ricardo Güiraldes. (1986). En el capítulo XXIII, p.277 el protagonista afirma: "Entre tanto, en las casas, me había hecho de un amigo. Antenor Barragán era un pedazo de muchacho grandote y delgado, dueño de una agilidad y una fuerza extraordinarias. Lo conocían en todo el pago como un visteador invencible y hacía gala de tal en cuanta ocasión se le presentaba.[...]" Tal fuerza y agilidad en las tareas camperas lo acercan al personaje de Castillo.

4 En este cuento la barbarie no se inserta en el indigenismo sino en la conducta violenta y brutal de un hacendado, un terrateniente. Con respecto a la barbarie, Lojo (1994, p. 26): “[...] Para Sarmiento la barbarie es la gran boca del vacío, el desierto barrido por los huracanes de la Naturaleza que se antropomorfizan o personifican en una fuerza grandiosa y salvaje, no por humana menos natural: la de Facundo. En la concepción sarmientina, sobre esa "tábula rasa" de la Naturaleza -estéticamente valorada- políticamente signo del más grave atraso- es posible implantar una cultura, o mejor, una civilización con elementos tecnológicos y un sistema productivo al que la vida nómade y patriarcal de la campañahábitat de pastores y ganaderos- es ajena por completo [...] ".

5 Femenías (2013, p. 81). Respecto de los espacios público y privado la autora sostiene: “[...] Espacio privado ha significado fundamentalmente "privado de ley y de equidad para las mujeres", donde la violencia simbólica y moral anteceden a la física, la que hasta no hace mucho tiempo se podía ejercer sin límites [...]”

6 Tenemos conocimiento de una obra inédita que aborda el mito de Medea que asume la titulación masculina. Se trata de Jasón de Alemania de Javier Roberto González (2000).

7 Larrauri (2006, p. 107): “[...] Los seres humanos siguen inexorablemente las leyes de la fuerza y si se representan a sí mismos como seres morales, no es sino porque se muestran obedientes respecto a un modo de actuar colectivamente bien visto $[\ldots]$ "..

8 Todas las citas están extraídas de la edición de la obra: Castillo (2018), que será abreviada (Cast."Pat”) seguida del número de paginación.

9 Pugliese (2011, p. 12). Con respecto al poder la autora afirma: “[...] el poder, entendido como emanación de la divinidad, se encarna ahora en un soberano estatal que hace sus veces y cuya expresión es la ley [...]”. A este mismo respecto Fantauzzi (2006, p. 122) afirma: “[...] para el conflicto entre pólis y pólemos se encuentra el origen del concepto de ley [...]".

10 La relación matrimonial entre una joven y un rico estanciero entrado en años nos recuerda el argumento de la novela argentina Felicitas Guerrero de Ana María Cabrera y la versión fílmica Felicitas estrenada en 2009, dirigida por Teresa Constantini.

11 Nos resulta interesante recordar que en el libro IX de Herodoto, denominado Melpómene, aparece una mención similar a la cláusula liderada por Antenor: "[...] Esa es la razón de que se le concedan todas las tierras que, a la redonda, pueda recorrer personalmente a caballo en un solo día”.

12 Respecto de la sexualización del espacio cf. Shaw (1975, pp. 255-266.), Zeitlin (1992 [1985], pp. 63-96), entre otros.

13 Con respecto al alambrado cf. Sbarra (2008), que sitúa su difusión en la década de 1870 y da paso del pastoreo nómade a la explotación agrícola, llevada a cabo dentro de propiedades con límites deslindados y demarcados por alambrados.

14 Femenías (2013, p. 134). A este respecto, la autora sostiene: “[...] Las mujeres son "objetos” de posesión de los varones, valiosas en tanto "objetos" intercambiables y de uso, pero que las mantiene al margen de la calidad de sujetos-agente [...]”.

15 El drama La frontera de David Cureses (1964) da cuenta de la génesis de dicha posesión.

16 Sarlo (2007, p. 159) afirma: "El duelo y la venganza establecen una ley no escrita. La violencia durante siglos puso un límite donde sólo la resignación y el coraje eran virtudes adecuadas; pero, al mismo tiempo, la violencia formalizó un código que daba sentido a las relaciones privadas y públicas".

17 Con respecto al toro, Chevalier afirma (1986, p. 1001): "El toro evoca la idea de potencia y fogosidad irresistible, el macho impetuoso [...]. En la tradición griega, los toros indómitos simbolizan el desencadenamiento sin freno de la violencia. Son animales consagrados a Poseidón, dios de los océanos y tempestades, a Dionisos, dios de la virilidad.”

18 La situación de inmovilidad y de pérdida del habla que experimenta Antenor nos recuerda a la que padece Recabarren, el protagonista del cuento "El fin" de Jorge Luis Borges.

19 A este respecto cf. Loreaux (2004).

20 Fernández Bravo (1991, p. 38) respecto de la frontera sostiene: “... ¿Quién es el bárbaro y quién el civilizado en la epopeya de la frontera? ¿Quién es el héroe nacional en un relato que a menudo localizó, tanto en Chile como en Argentina, rasgos heroicos en la resistencia indígena...”.

21 El abandono de los hijos es una de las vetas poco frecuentes del mito. Ciertamente algunos poetas de ciclos épicos, como Creófilo en La toma de Escalia, nos dan información sobre la muerte de Creonte, rey de Corinto, envenenado por Medea, y la posterior huida de esta a Atenas. Cuando Pausanias recorrió Corinto visitó la tumba de los hijos de Medea, Mérmero y Feres, apedreados por los corintios como castigo por haber llevado a Glauce los funestos dones. Luego Medea vivió en casa de Egeo y, después de haber conspirado contra Teseo, se vio obligada a huir con su hijo Medo, fruto de los amores con Egeo. 
Respecto de la muerte de los hijos existen distintas versiones: en una de ellas Medea mata a sus hijos sin intención, al fallar la fórmula que debía hacerlos inmortales. En otra los niños fueron asesinados por los corintios en venganza por la muerte de Creonte y Glauce y, en una tercera versión, Medea mató a Creonte, abandonó a sus hijos en el templo de Hera y huyó hacia Atenas, tras lo cual los corintios mataron a los niños y acusaron a Medea del hecho. Por otra parte, Hesíodo cita un hijo de Jasón y Medea llamado Medeo; otros autores mencionan una hija Eriopis. Los hijos Feres y Mérmero son extraídos de la tradición clásica. Mientras tanto Diodoro cita a Tésalo, Alcímenes y Lisandro.

La veta mítica del abandono de los hijos y su posterior muerte a manos de los corintios aparece en Medea. Voces de Christa Wolf (1996).

22 Este acto de cierre del cuento de arrojar la llave nos recuerda el final de "Casa tomada" de Julio Cortázar. 